\title{
DIMENSIONS AND CHALLENGES OF SOCIAL RESPONSIBILITY
}

\author{
Jucan Cornel Nicolae ${ }^{1}$ \\ Jucan Mihaela Sabina ${ }^{2}$
}

\begin{abstract}
We focused the research spot on the dimensions and challenges of social responsibility, focusing more on issues of how companies, in terms of competition, consumers, employees, community and environment affect the economy. We analyzed and shown how businesses, governments, consumers and other interested parties are always exciting and required to contribute to efforts to reduce poverty, to create competitive products and services, new jobs, while protecting natural resources through development of sustainable production and consumption. Finally, we showed that social responsibility programs target real social needs and effect, generating social benefits that can be converted into market opportunities and long-term profits. But, all this requires changes in attitudes and reorientation, both for production and consumption, by products and services less destructive to the environment, to improve efficiency of resource use, eco-efficiency and overall economic efficiency, and, at the same time, competitiveness, supported by a process of innovation more actively.
\end{abstract}

Key-Words: business, corporate social responsibility (CSR), environment, globalization, management, sustainable development.

JEL Code: A 13

\section{Dimensions and Challenges of Social Responsibility}

Social responsibility is the assumed obligation of business to society. Being socially responsible means to maximize the positive effects and minimize the negative effects on society (customers, owners, employees, community, suppliers, and government). There are four kinds of social responsibility: legal, ethical, economic and philanthropic.

Legal dimension of CSR relates to compliance with laws and regulations established by the authorities, which set standards for responsible behavior - the codification of what society thinks is right or wrong. Legal regulation of businesses leadership are made because the society, including consumers, interest groups, competitors and legislators, cannot be confident that businesses do what is right in a particular field, such as consumer or environment protection. This lack of confidence is the strength of legal size. Many ethical and economic issues go to court or legislative debates.

In other words, the laws set rules for responsible businesses activities. They can be divided into laws that regulate competition, consumer protection laws, environmental laws and laws that promote safety and fairness.

Ethical dimension of CSR refers to behaviors and activities that are permitted or prohibited by organization members, community, society, even if they are not codified by law.

Milton Friedman said that "the basic mission of any business is to produce, with profit, goods and services, making the business to achieve its maximum contribution to society and, in fact, to be socially responsible.

\footnotetext{
${ }^{1}$ Faculty of Economics Sciences, „Lucian Blaga” University of Sibiu, 550324 Sibiu, Calea Dumbrăvii 17, ROMANIA, cnjucan@yahoo.com

${ }^{2}$ Faculty of Economics Sciences, ,Lucian Blaga” University of Sibiu, 550324 Sibiu, Calea Dumbrăvii 17, ROMANIA, cnjucan@yahoo.com:
} 
Social Responsibility cannot be just a response to problems when they arise. Only if the firm includes ethical concerns since its foundation and includes ethics in businesses strategy, social responsibility, as a concept, is integrated into daily decision making.

Business strategy determines how the firm will use human and financial resources to achieve its objectives. The value system of corporate and stakeholders has a profound effect on corporate strategy implementation. There are some postulates in this respect:

- business strategy must reflect the understanding of organization members and stakeholders value;

- business strategy must reflect the understanding of the ethical nature of strategic choices;

- business strategy should take into account important stakeholders.

If these postulates are accepted, then ethics becomes a central concern in business strategy.

Economic dimension of CSR refers to how resources for the production of goods and services are distributed within the social system.

Social responsibility, in relation to the economy, encompasses many aspects of how firms, in terms of competition, consumers, employees, community and environment affect the economy. For example, the economy is affected by the economic power of companies in relation to resources and supply of products control.

Antitrust laws appeared to stop big companies to monopolize trade and business, to practice price discrimination, unfair competition and mergers resulting in an uncompetitive environment.

The relationship between the environment and corporations also affects the economy. Major environmental concerns relate to air pollution, water and soil.

Large corporations were encouraged to establish mechanisms to control pollution and other environmentally friendly policies. Otherwise, these companies may deplete resources and harm the society by focusing only on its own economic interest.

Consumers and employees influence also the economy. If a company does not target consumers, profitability and ability to compete may be significantly affected.

Steven Covey, author of "The 7 Habits of Highly Effective People" show that companies rated with low confidence has internal conflicts, lower quality products or services, loss of customers, etc".

Business effect on the economy, in terms of employees, is significant. Issues related to equal employment opportunity, health and safety at work, job diversity, employee privacy, etc.

Management compensation is another issue of ethics and accountability in relation to the economy. They note that managers frequently receive high salaries, even though the organization is profitable or not.

Philanthropic dimension of CSR refers to companies contributing to the local community or society. It offers four benefits to society.

First, the philanthropic dimension improves quality of live. It helps the community to make there an area where customers want to do business and employees want to raise their children. Second, reduce the size of government involvement in charity offering help to people with legitimate needs. Third, increase the staff leadership ability. Fourthly, the philanthropic dimension builds the staff moral principles. Employees who are volunteering have generally better opinions about themselves, their company and community.

One of the social responsibility requirements is that management decisions take into account the social impact generated by the organization. This involves:

A. Social impact assessment of strategies, policies and actions of organizations, companies or public institutions.

B. The social audit: assessing the social impact by a third party, an assessment agency independent and objective, not only in relation to the assessed organization but also with groups potentially affected by it.

C. Compliance: Risk assessment or social impact and social audit in accordance with a set of 
management standards or methodologies and evaluation indicators generally accepted.

D. Transparency and reporting: the publication of significant results of the audit office, informing interested groups on the social impact, or social and environmental risk generated by the organization, offering information in the manner and through the appropriate and accessible channels, so that organizations ensure that their partners know and understand the social impact caused by them and are therefore able to defend their rights and make informed decisions.

E. Dialogue stakeholders and stakeholders' involvement in the decision: in parallel with the evaluation and social reporting, organizations should build tools and channels of communication with interested groups in order to encourage their feedback.

Transparency in communication can lead to an active, cultivate, educated and loyal public; social expectations generates social innovation, social innovation generates technological innovation and technological innovation generates loyalty, reputation, competitiveness and market share.

Organization must recognize that interested groups information and their involvement in those decisions, which concern their interests and expectations, may be beneficial for long-term development of companies.

A certain degree of transparency leads to cultivate an educated, active and loyal public. Also, public involvement lead to more efficient quality management, products and services better tailored to market needs and consumer expectations. Finally, dialogue with interested groups makes a piece of information that can generate innovation and increase competitiveness. Generally, social expectations and consumer requirements can become marketing opportunities and community needs can turn into business opportunities.

In 2009, policies and corporate social responsibility programs have had to face three main challenges: continuity, pragmatism and social impact assessment resulted. Socially responsible leaders should find answers to some problems that investors, board of directors, communities and social partners will arise.

1. To what extent the expenditure limitations will affect the social responsibility budgets?

2. What areas of social responsibility will be hit: environment, career development programs, retention and inclusion in workplace education programs, humanitarian programs and social assistance, social integration and information programs, civic programs, corporate health programs?

3. What types of programs will be maintained: the own programs or projects for funding of programs initiated by the social partners, NGOs? Obvious benefits of quality programs, loyalty partners, human resources, branding, sponsorship or philanthropic actions with greater visibility in the media?

4. How and to what extent the budget limitations of CSR will affect employees, communities, consumers?

Regardless of budget, regardless of social issues addressed, CSR will be responsible to ensure better linkage between CSR and financial objectives and long term development of their companies. They will have to manage budgets for CSR in a pragmatic manner so as to ensure continuity of valuable projects, leading change, bringing a clear social impact, measurable, which bring real benefits to key stakeholder groups of companies, investors, customers and partners business, employees and communities.

In those companies where social responsibility programs target long term real needs and social effects ( environmental, social integration, research and innovation, human resources, education, health) leaders must persuade their managers that such programs generate social benefits, can be converted into market opportunities and long-term profits.

To this purpose, CSR managers must find pragmatic tools for social and environmental management projects:

a. evaluation indicators for monitoring and evaluating social and environmental performance 
b. models of sustainability, for the adoption and implementation of social programs by the community

These resources can come from: partnerships with companies in the production chain, public-private partnerships, access to structural funds or research grants, partnerships with universities or credible NGOs.

Small and medium companies that will convince the social involvement have the best chance to make profits and to retain valued employees.

International Business Report published a study performed by the prestigious businesses consulting firm Grant Thornton. Purpose of the study has been over 34 economies around the world. Research has shown that small and medium firms, known as the "engine of world economy", will have to review very quickly the attitude towards social responsibility.

Until now, they were in sight the ethical practices of multinationals, expecting actions in sustainable development of society. According to the report multinationals focus attention generally to the following areas:

- Human Rights

- Working conditions

- Environment

- Corruption

The most important factors determining social responsibility have been identified by company managers as:

1. Keeping key employees $-65 \%$

2. Controlling costs for the efficiency of resources and environmental protection - $63 \%$

3. Need to build trust and loyalty - strengthening brand $-56 \%$

4. Tax cuts $-44 \%$

5. Saving the planet $-40 \%$

6. Better relations with investors $-39 \%$

7. Government pressures $-38 \%$

Jan Miller Hethland, the Danish representative of Grand Thornton, summarize these trends: "Business Ethics is a key factor in recruiting and retaining employees in a limited job market, like that $\mathrm{f}$ Denmark. If private companies will ignore corporate social responsibility practices, will lose an essential resource in the fight for global competitiveness.

In terms of implementation, top 10 favorite CSR practices looks like this:

1. Different measures to improve employees' health $-71 \%$

2. Internship programs - $61 \%$

3. Charitable donations $-65 \%$

4. Promoting diversity and equality $-64 \%$

5. Labor flexibility support staff $-62 \%$

6. Effective management of waste $-59 \%$

7. Efficient management of energy sources $-57 \%$

8. Participation in community life $-55 \%$

9. Products/services improvement $-41 \%$

10. Assisting other companies to improve performance

The survey, published by International Business Report, reveals that both large companies, but especially small and medium companies are starting to make significant steps in adopting ethical practices and social responsibility. And those who do not take quick action in an increasingly global and more competitive economy will succumb.

The modern concept of social responsibility, seen as a key concept of business ethics, is a moral concept which coagulates both the idea of private virtues involved in this sphere of live (fairness, reciprocity, mutual interest, utility) and the idea that there are social and moral skills and availability in the corporation itself. 
Favorite subject of business ethics is the financial scandals and "enrichment overnight", but the real and significant issues are obviously much more diverse.

In this context, Richard T. De George distinguish between the micro and macro-moral issues, and considers that, generally, business ethics issues, taken in a given and reported system, the current capitalism, can be divided into six categories:

- Determining the correct distribution of resources, action for the foundations of distributive justice ( the allocation of resources and revenues made according to merit, need, effort, ability, etc.).

- The second set of problems concerns clearly circumscribed principle of justice to particular cases. This means that some "difficult moral cases" can be resolved through debate and discussion.

- Third moral issues in business refers to conflict between different values (freedom, justice, equality, welfare, personal security, productivity, efficiency, etc.).

- The fourth type of moral problem occurs due to development of moral intuitions and the obligation to implement them in practice previously anticipated. Segregation and discrimination in employment based on sex or race are now deemed unethical practices, but, not long before, they were not evaluated in this way.

- The fifth category of moral issues is created by the consequences of the emerge of new technological products, including information society techniques and genetic manipulation. Today is possible to destroy the human race and the environment so that he can no longer be support for future generations. Also in business there can be finished non-renewable natural resources.

- The sixth category of micro and macro-moral issues includes the application of accepted moral values and refers to the prohibitions imposed on business management. In this category, for example, we note lying and stilling, bribery and other behaviors judged as immoral acts .

The same author points out that "this does not mean that we meet everywhere in business only moral acts, and, where ethics is not self-imposed, it must be imposed from outside by appropriate penalties to protect the general good".

Ethical responsibility requires that businessmen and firms do everything is just, fair and equitable, even if these attitudes are not covered by a legal framework. Because of the globalization, businesses suffered and are suffering rapid change with new social responsibilities and ethical obligations of companies.

We can say that because of these rapid changes, in the globalization process business ethics and responsibility are very important, considering the multiculturalism that exists and operates in various international markets. So, for example, attitudes, values and moral ethics in the European market are very different from the existing values in the Middle East countries.

Economic activities undertaken by different companies on the market of other state must comply with statutory and legal aspect of the state. Therefore, it is normal that business ethics and responsibility begin where the law ends and ethical principles are applied without being under government control. Ethical and moral standards should be defined in the business strategy, and the companies must respect the environment (emission of toxic gases in the atmosphere), culture, customs, ensuring sustainable development of these areas.

\section{CSR - factor for sustainable development}

Globalization, sustainable development and competitiveness are the three major challenges and milestones of our present.

Sustainable development, concept and objective, intends to build "a better quality of live for ourselves, our children and our grandchildren" and it involves integrating the economic, social and environmental dimension.

To achieve this objective "it is necessary to have an economic growth to promote social progress and respect the environment, social policy to stimulate the economy and environmental 
policy to be effective and economical". Production and consumption are well understood in the heart of sustainable development. Many environmental and health problems are linked to production. Moreover, if key resources are exhausted before approachable to find substitutes, appear serious threats to economic development. These problems occur not only in countries where their resources are consumed, but also in countries where raw materials and finished goods are imported. Appear obvious interrelationships between the economic process, social and environmental problems, and that may not be possible to treat the performance of a state only after a single dimension.

European Union Strategy for Sustainable Development, Goteborg (2001), had the stated goal of achieving reconciliation between economic development, social cohesion and environmental protection.

Also, the Action Plan resulting from Johannesburg Summit (2002) refers primarily to collective social responsibility towards environmental and social impact of businesses, government and consumers decisions, highlighting the companies important role in providing sustainable development in poverty eradication and sustainable management of natural resources. Social, environmental and economic will be integrated in all stages of product life cycle.

Businesses, government and consumers as well as other interested parties are always exciting and required to contribute to efforts to reduce poverty, create competitive products and services, new jobs, while protecting natural resources from development to production and of sustainable consumption.

This involves the implementation of strategies aimed at improving efficiency and resource management, product development and technology to meet the environment protection, placing greater emphasis on opportunities for renewable and recyclable resources.

But nevertheless require behavioral changes and reorientation, both in production and consumption, by products and services less destructive to the environment; improve resource efficiency, competitiveness at the same time with a more active process of innovation.

The relationship between globalization and sustainable development is very complex: in some area they are in conflict, in others they are necessary for each other, in others they are mutually reinforcing. Multinational enterprises, which are also the heart of these two major issues, are in continuous progress in number, size and concerns. From this perspective, what these companies will make and how they will preserve, produce and distribute their products will be crucial for the general or local development.

With the rapid growth of transnational companies in number and size, ubiquitous in the world, visible in everyday life, as concerns the effects on society, environment and development will be affected.

In response, they adopted voluntary initiatives whose nature differs from one country to another, from one area to another, but are promoted to improve their environmental balance, the working conditions and relations with them and with consumers, local authorities, including government, unions and other stakeholders.

By integrating social and environmental concerns in economic activity of enterprises, this is actually the most widely accepted definition for corporate social responsibility (RSE - acronym adopted by the author). This responsible attitude is manifested as an engine for sustainable development.

It is clear that social responsibility (RSE) is perceived as the micro-economic dimension of the macroeconomic concept of sustainable development. In another interpretation, the RSE is seen as part of sustainable development concept, a business contribution for achieving sustainable development.

Premises favoring adoption and development of corporate social responsibility attitudes, are: global trend to reduce the state role in economy, as a result of factors known as "globalization"; liberalization of international trade and financial transactions; consolidation of firms within global 
corporations and transnational information flows; growth by developing new technologies, reducing the state's role in achieving expectations of its citizens; ensuring social and environmental protection (Argentina case and environmental disasters, the most frequently cited in studies).

One factor that favors the trend toward greater awareness of socially responsible behavior of businesses, from large transnational companies, national companies, to SMEs, so that business to be long term successful, is given by the need to balance development of new global economic structure and people's and other stakeholders expectations.

The principle of reconciliation of economic activities with social and environmental requirements, in the context of sustainability, is known in literature as the "Triple P" - Profit, People, Planette. The term was used in 1997 by John Elkington and considers that an organization is (long term) sustainable, if the organization is properly funded while minimizing negative environmental impact and take account of social expectations.

Examples of "best practices" in the RSE reveal that a viable solution is to shift the prevailing economic model of business by a much broader socioeconomic business, moving the emphasis from production, exploitation, meet individual interests and little interest in government - business as a close system - toward the quality of live, resource conservation, the interests of society - business as an open system.

\section{CSR in European companies}

RSE concerns and issues have a global dimension. In fact, a growing number of European companies, and not only, develop their activities in several countries, receiving profits as a result of the opening of the market.

Globalization and trade, investment and sustainable development have become essential in addressing RSE problems. Knowledge of issues and RSE concerns promote investment, develop cooperation and foster technology transfer.

In this context, are long term sustainable only those companies that:

- Stimulates the formation, providing the appropriate environment for the transmission of knowledge, access to culture, lifelong learning, developing and expertise transmission, basic elements of the knowledge society;

- Provide a suitable environment for diversity, equality, openness, transparency, taking into consideration the consequences of decisions in sustainable development;

- Have an important role in social responsibility;

- Responding to a large number of problems to business skills;

- Negotiating instruments capable of measuring business performance and make reports;

- Negotiating goals;

- Ensure the necessary exchange of views between all stakeholders.

Globalization leads to complex economical changes, in which the enterprise, as a major factor in this process, must redefine its position, being in a new interdependence with stakeholders.

RSE awareness, as reported in the European Council in Lisbon in March 200, has also led to the concept of "Best Practices" in areas such as lifelong learning, work organization, equal opportunities, social inclusion, sustainable development. The awareness of the importance of each issue specified in the definition, the center of gravity becomes the firm, its social and environmental responsibility.

In this context, although there is no common definition accepted for corporate social responsibility, this means voluntary integration in current business affairs of social and environmental concerns and their interactions with stakeholders (Stakeholders are "persons or groups who have, or may have a property right or interest in the enterprise and its past, present and future activities").

Specialized studies provide a full picture of implications, attitudes, costs and benefits, obstacles, brakes, that enterprises meet in relation to their responsibility to "stakeholders". A 
specific attention in this relationship involves two groups of stakeholders: community, in the broad sens of the world, and the natural environment.

A definition used in the literature with regard to RSE, is: "CSR is the alignment of a company's activity in social values. This consist of integrating the interests of all those affected by the conduct of companies in its policies and actions. Corporate social responsibility is reflected by triple indicators (triple bottom line), which measures financial, social and environmental results, in order to have a positive impact on society while accounting for business success".

In the new guidance, companies acquired a central role in socioeconomic development and the achievement of the EU Strategy, the EC acting as a catalyst. As was shown, RSE aims to build innovation, job creation and competitiveness in Europe, thus becoming an important fact in achieving the strategic goal set by the Lisbon Agenda in 2000.

Social responsibility is manifested in large public or private enterprises and is followed by SME's and cooperatives. This is the argument to call the enterprises to contribute to a new Europe, launched by the Lisbon Agenda 2000, constructing a new European Model of responsible management, which means that companies will take into account the effects of their decisions on all stakeholders.

Experiences of EU countries show that, without constraints, the RSE can achieve results that contribute to the welfare of the community, in places where companies have developed a business. We can illustrate this with the "Scandinavian model", characterized by some aspects: the state plays the role of welfare provider, combining harmonious development based on capital items, with a generous social security system and with great respect for the environment.

Scientific research is an area that has a lot to offer. Innovation, an ongoing process, is a necessary way to achieve a level of competitiveness as proposed at European level in Lisbon. Innovation in technologies, products to meet those requirements that were not met so far, are essential for dynamic economic model forecast. In Europe, demand for sustainable products and services increase. In developing countries, innovation in products must be correlated with the price level which must be acceptable, as response to issues of poverty and improve living standards. Thus, there is a primary requirement for economic development, namely entrepreneurship.

CSR integrated in business strategy and operation may be an answer to this problem. Corporate responsibility has consequences in decision making in all its aspects: strategy, research, management, process, etc.

Responsibility is reflected in company performance targets, collective and individual, of recognition and remuneration. It is necessary to train people so as to be able to integrate with responsibility in business, but also in ordinary life, in order to achieve performance objectives of CSR at all levels and in all enterprise activities.

RSE concept covers a wide range of enterprise activities, especially when it operates in several countries. This situation has created an impressive variety of voluntary initiatives, which often include innovative elements, but also involves particular challenges in increasing measures transparency and the comparison. Transparency is also a key element of RSE by helping businesses to improve how they operate, leaving space for the results measurement by an independent part of economic process.

Because expectations of the RSE policy became increasingly well outlined, it is a need for convergence of concepts, tools and practices that can lead to greater transparency, without blocking innovation and initiative, to provide beneficial to all players. Some market-oriented initiatives have started to appear and converge towards transparency in this area. EU states had initiatives that were promoted in accordance with their own approaches to RSE, tinted to those at EU level.

Increasing convergence and transparency is needed in such directions:

1. Code of conduct

2. Standards management

3. Financial reports, audit and reporting (information) 


\section{Labeling}

5. Socially responsible investment

So far, companies declared RSE, have been reporting this behavior, enrolling in reporting systems dedicated to sustainable development. Literature does not reveal a specific indicator for RSE system, recognized globally and validated by practice. There are reported some "Best Practices" studies - Forums EC Declaration ITO, OECD principles, international standards-making annual reports - GRI, etc. For "social indicators" group, for example, "ORSE - Observatoire sur la Societe des Entreprises Responsibility - has launched a working group for two years of study.

It is fundamental that no organization (or sector) cannot assume that is social responsible, active dialogue with other parts of society being essential. Here comes the role that standardization can play in the RSE, that can be achieved, but in a transparent manner, through a process that includes participation of stakeholders, engage new expertise, train new stakeholders, etc.

\section{RSE - recognition and development}

RSE concept is recognized by businesses, policy makers and other stakeholders as an important factor for new methods of governance and the prevention of reactions to fundamental mutations, such as globalization, which opened new perspective for business, but made them complex; increasing deployment of business activity abroad give rise to new responsibilities at the global level, especially in developing countries; image and reputation will play an increased role in the competitive environment of business, while consumers and NGOs expect more information on terms of production of goods and services. Rewarded for their behavior, companies adopt a responsible environmental and social attitude; knowledge and innovation are crucial for ensuring a high degree of competitiveness, making companies to raise interest in forming and retaining competent labor, highly skilled.

\section{Adopting socially responsible practices}

Remove obstacles to knowledge dissemination and adoption of social responsible practices by enterprises have as starting point the following:

- insufficient knowledge about the relationship between socially responsible practices and the economic performance of enterprise ("economic arguments");

- consensus among various "stakeholders", taking into account the global dimension of RSE concept, and mainly the diversity of the national strategic framework in which it applies;

- information, general and individual, in economic schools eg., about the role of RSE in economic long-term development of enterprises; behavior

- recognition and acceptance, both for consumers and investors, of socially responsible

- consistency of public policies.

In the transition to a knowledge-based economy, training and continuous training of employees and citizens play a crucial role. In this way, information on the consequences of wrong decisions taken at the enterprise level, local or global, may be better known and understood, so that long-term effects are prevented by a responsible attitude adopted by all "stakeholders", including public authorities.

\section{References}

1. Crane, A., Matten, D., 2004. Business Ethics, A European Perspective. Oxford University Press.

2. Crăciun, D.; Morar V.; Macoviciuc, V., 2005. Etica afacerilor. Paideia Publishing House, Bucharest.

3. Comunicat CE -RSE "Contribuția intreprinderilor la dezvoltarea durabila”, 2002 
4. Dion M., 2007. L`ethique de l`entreprise; Edition Fides

5. De George, R.T. , 1990. Business Ethics. 3 rd Ed., Macmillan, New York.

6. Ferrell O.C., Fraedrich John, Linda Ferrell, 2008. Business Ethics. Houghton Mifflin Company, Fifth Edition.

7. Ghiță, M., Briciu, S. et all, 2009. Guvernanţa corporativă şi auditul intern. Aeternitas Publishing House, Alba Iulia.

8. Hada, T., Achim M. I., 2007. Managementul şi finanţarea afacerilor. Risoprint Publishing House, Cluj-Napoca.

9. Jucan, C. N., Jucan, M. S., 2010. Social Responsability in Tourism and Sustainable Development. in Latest Trends on Cultural Heritage\&Tourism, 3rd WSEAS International Conference on Cultural Heritage and Tourism (CUHT"10), Corfu Island ,Grece.

10. Green Paper - Promoting a European framework for Corporate Social Responsibility (COM (2001)

11. Les lignes directrices du CAD -Stratégies de développement durable - OCDE, 2001

12. Strategie de l'Union europeenne en faveur du developpement durable, COM (2001)

13. Solomon, C. R., 1994. Morality and the Good Life. New York, McGraw - Hill Professional Publishing.

14. Van Den Hoven J., Weckert J., 2008. Information Technology and Moral Philosophy, Cambridge University Press.

15. Ziglar Zig, 2002. Arta vânzării. Amaltea Publishing House, Bucharest. 